\title{
Posterior reversible encephalopathy syndrome (PRES) in a patient with lupus nephritis
}

\author{
Bandara L M H $\mathbf{H}^{1}$, Hittarage $\mathbf{A}^{1}$ \\ Journal of the Ceylon College of Physicians, 2018, 49, 39-40
}

\section{Introduction}

Posterior reversible encephalopathy syndrome (PRES) is a clinico-radiological entity with headache, visual disturbances, seizures, altered sensorium and white matter reversible vasogenic oedema affecting commonly occipital and parietal lobes ${ }^{1,2}$. Recognized aetiologies are acute hypertension, pre-eclampsia, eclampsia, renal disease, immunosuppressants sepsis and less commonly autoimmune diseases ${ }^{1-5}$. Here we report a case of lupus nephritis (LN) that presented with PRES.

\section{Case report}

A 27-year-old, mother of two, from Negombo with systemic lupus erythromatois (SLE) and class III LN (with normal serum creatinine) for which who was on mycophenolate mofetil, azathioprine and low dose prednisolone presented in July 2016 with headache, blurred vision and generalized tonic clonic convulsions without fever, photophobia or vomiting for 2 days duration.

On examination she was slightly drowsy with GCS $15 / 15$. She was not febrile, mildly pale, not icteric and had bilateral pedal oedema. There was no neck stiffness, no papilloedema, and her pupils were equal and reactive. She didn't have any neurological deficit and her tendon reflexes were slightly exaggerated. Her pulse were $96 \mathrm{bpm}$ with blood pressure (BP) of 190/ $120 \mathrm{mmHg}$. Her urinary HCG was negative and had proteinuria-2+ present on dipstick. Investigations showed white blood cell count $10.3 \times 10^{9} / \mathrm{l}$, platelet count of $127 \times 10^{9} / \mathrm{l}$, haemoglobin of $9.3 \mathrm{~g} / \mathrm{dl}$, serum creatinine of $657 \mathrm{umol} / \mathrm{l}$, ESR of $55 \mathrm{~mm}$, CRP of $8.2 \mathrm{mg} / \mathrm{l}$. Blood picture revealed normochromic normocytic anaemia with few fragmented cells. Reticulocytes were 1.7\% with lactate dehydrogenase of $637 \mathrm{U} / \mathrm{l}$. Her serum

\footnotetext{
${ }^{1}$ Colombo North Teaching Hospital, Ragama, Sri Lanka.
}

Corresponding author: Bandara L M H E-mail: 1harshanabandara@gmail.com albumin was $2.4 \mathrm{~g} / \mathrm{dl}$. Non-contrast computed tomography (CT) brain showed bilateral hypodense areas in occipital region (Figure 1). Abdominal sonography was normal except poor corticomedullary demarcation in bilateral kidneys.

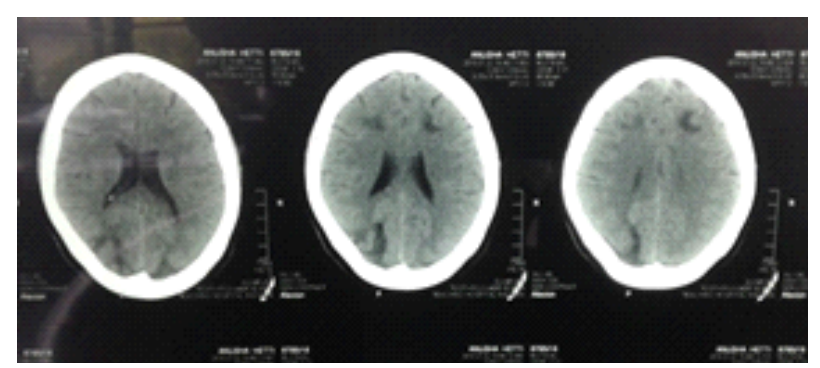

Figure 1. Findings on computed tomography (CT) of brain.

Our differentials were neuropsychiatric SLE with lupus nephritis relapse, central nervous system infection, cerebral venous sinus thrombosis and PRES. Blood cultures, urine cultures were taken and started on intravenous ceftriaxone empirically. The immunosuppressants with prednisolone were continued. Urgent magnetic resonant imaging with arteriogram and venogram (MRI/MRA/MRV) of brain was carried out. There were focal areas of T2/FLAIR hyperintense and T1 hypointense, involving bilateral occipital, bilateral frontal cortices, bilateral cerebellar hemispheres and left basal ganglion. These areas didn't demonstrate diffusion restriction or contrast enhancement (Figure 2). MRV \& MRA were normal. Radiologist concluded it as PRES with vasculitic changes.

Ultimate diagnosis of was made as flare-up of LN with hypertensive crisis complicated with PRES. Blood pressure was controlled with glyceryl trinitrate infusions and losartan. Seizures were initially controlled with intravenous midazolam. Seizures subsided with reduction of blood pressure. Her LN was managed with intravenous cyclophosphamide and intravenous methylprednisolone. Repeat non-contrast CT brain after two weeks showed total clearance of initial changes. MRI was not repeated due to lack of facilities. Renal functions improved and cyclophosphamide pulses were planned with increased dose of prednisolone on discharge.

This is an open-access article distributed under the terms of the Creative Commons Attribution License, which permits unrestricted use, distribution, and reproduction in any medium, provided the original author and source are credited. 


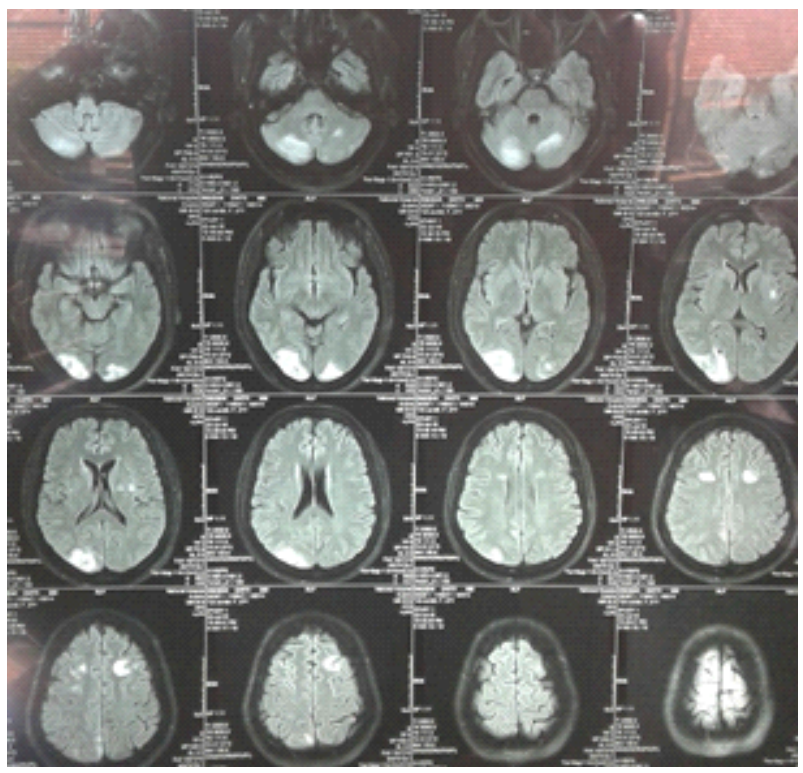

Figure 2. Findings on magnetic resonant imagingFLAIR (MRI).

\section{Discussion}

PRES is a clinico-radiological entity occurring in acute hypertension, pre-eclampsia, eclampsia, renal failure as well as in immune deficient states ${ }^{2,5}$. It is rarely associated directly with autoimmune diseases such as SLE ${ }^{5}$. Our patient had several risk factors for PRES namely, acute hypertension, renal impairment, immuno-deficiency and underlying autoimmune disease. Clinical features typically are headache, visual disturbances and seizures. By definition PRES is reversible if promptly diagnosed and managed though substantial mortality occurs due to complications such as status epilepticus, cerebral infarction and bleeding ${ }^{2}$.

The pathophysiology of PRES is yet to be established though several theories are proposed. Widely accepted theory is that the rapidly developing high BP may disrupt the autoregulation of cerebral blood flow causing extravasation of fluids and protein leading to vasogenic oedema. Other theories suspect endothelial dysfunction and vasospasm induced ischaemia ${ }^{2,3,4}$.

Features of PRES may not be evident in CT scan, though it is beneficial in excluding other causes. $\mathrm{MRI}$ is diagnostic and T2 images show bilateral symmetrical lesions of vasogenic oedema affecting mainly the occipital and parietal lobes. Frontal, basal ganglia and brain stem also can be involved².

There are no clinical trials evidence for management of PRES. Aggressive BP control and removing the offending factor works if the syndrome was diagnosed promptly ${ }^{2,4}$. Theoretically steroids may reduce the oedema. Radiological improvement will be evident in weeks.

\section{References}

1. Chang T, Lanerolle R. Posterior reversible encephalopathy syndrome as the first manifestation of chronic kidney disease. Ceylon Medical Journal 2012; 57(1): 40-1. DOl:http://doi.org/10.4038/cmj.v57i1.4200

2. Fugate JE, Claassen DO, Cloft HJ, Kallmes DF, Kozak OS, Rabinstein AA. Posterior Reversible Encephalopathy Syndrome: Associated Clinical and Radiologic Findings. Mayo Clinic Proceedings 2010; 85(5): 427-32. doi:10.4065/mcp.2009.0590.

3. Sengupta P, Biswas $S$. Dialysis disequilibrium leading to posterior reversible encephalopathy syndrome in chronic renal failure. CEN Case Reports. 2016; 5(2): 154-7. doi:10.1007/s13730-016-0215-4.

4. Bartynski WS. Posterior reversible encephalopathy syndrome, part 2: controversies surrounding pathophysiology of vasogenic edema. AJNR Am J Neuroradiol 2008; 29: 1043-1049. doi: 10.3174/ajnr.A0929

5. Leroux G, Sellam J, Costedoat-Chalumeau N, Le Thi Huong D, Combes A, Tieulié N, Haroche J, Amoura Z, Nieszkowska A, Chastre J, Dormont D, Piette JC. Posterior reversible encephalopathy syndrome during systemic lupus erythematosus: four new cases and review of the literature. 2008; 17(2): 139-147. doi.org/10.1177/0961203307085405 